\title{
PROPAGATION TECHNIQUES AND THEIR EFFICACY RATE IN PROSOPIS CINERARIA (L) DRUCE - A MULTIPURPOSE TREE OF CHOLISTAN DESERT, PAKISTAN
}

\author{
RAFAY, M. ${ }^{1 *}$-ALI, M. Y. ${ }^{1}-$ ABDULLAH, M. $^{3}$-MALIK, Z. ${ }^{4}-$ RIAZ, U. $^{1}-$ ABID, M. ${ }^{1}$-FAROOQI, M. A. ${ }^{2}$ \\ - AKHTAR, S. $^{2}$
}
${ }^{I}$ Department of Forestry, Range and Wildlife Management, The Islamia University of Bahawalpur, Bahawalpur, Pakistan

${ }^{2}$ Department of Entomology, The Islamia University of Bahawalpur, Bahawalpur, Pakistan

${ }^{3}$ Cholistan Institute of Desert Studies, The Islamia University of Bahawalpur, Bahawalpur, Pakistan

${ }^{4}$ Department of Soil Science, The Islamia University Bahawalpur, Bahawalpur, Pakistan

*Corresponding author

e-mail:Rafay@iub.edu.pk

(Received $18^{\text {th }}$ Apr 2018; accepted 20 ${ }^{\text {th }}$ Sep 2018)

\begin{abstract}
The present work is an effort to determine the best and easiest method of producing plant of Prosopis cineraria from branch cutting. The root initiating hormones IBA were used for vegetative propagation of Prosopis cineraria. The results of this research well help in reducing the size of shoot being used in vegetative propagation. It will also reduce the plant genotypic variability and will help to ensure increased germination percentage by determining the best dose of root initiating hormones and different cutting sizes. Sprouting percentage is very important to predict the behavior of the tree if any species is to be propagated by asexual method of shoot cutting. Overall $15.24 \mathrm{~cm}$ cutting at open air was found best $(2.38 \mathrm{C})$ in all the treatments, but it sprouted maximum in growth regulator IBA $(3.71 \mathrm{~A})$. Production of more number of leaves is also an important factor in determining the fodder value of the plant. Under the individual factor highest number of leaves $(4.21 \mathrm{~A})$ was produced by the $15.24 \mathrm{~cm}$ cuttings with IBA and least was produced by the $5.08 \mathrm{~cm}$ cutting in open air. The number of leaves produce was higher in $10.16 \mathrm{~cm}$ cuttings with $(3.44 \mathrm{~A})$ in polythene sheet compared to open air. Plant height showed its peak value $(2.21 \mathrm{~A})$ in $15.24 \mathrm{~cm}$ cutting with provided IBA and least height $(1.23 \mathrm{C})$ was noted in $15.24 \mathrm{~cm}$ cutting without growth regulator. The second peak value was observed (1.78 B) in $5.08 \mathrm{~cm}$ cutting followed by $(1.75 \mathrm{~B})$ in $10.16 \mathrm{~cm}$ cutting. Root length indicated its peak value $(2.18 \mathrm{~A})$ in $15.24 \mathrm{~cm}$ cutting with provided IBA and least height $(1.19 \mathrm{~B})$ was noted in $15.24 \mathrm{~cm}$ cutting.
\end{abstract}

Keywords: variability, vegetative, growth regulator, IBA, sprouting

\section{Introduction}

Prosopis cineraria (L.) belongs to the (Family Fabaceaea) which is extraordinary versatile tree species of Cholistan Desert. This tree is locally called Jhand which holds the vital place in rural bargain in the southern region of the Punjab, Pakistan. The genus Prosopis contains about 44 species of shrubs and trees scattered mainly in the dry regions of the Southwest part of Asia, Africa and generally America from the western North America to Patagonia (Liu et al., 2012; Puri and Kumar, 1995). Therefore all the parts of this tree are useful, it is also known as "wonder tree" and "king of desert". It is a small, irregularly forked and thorny tree which is about $5-10 \mathrm{~m}$ in height. It has uneven, thick and grey bark with the deep gaps. Roots are very bottomless; the tap root of $P$. cineraria may enter perpendicularly nearly about $20 \mathrm{~m}$ or more (Mahoney, 1990; Preek et al., 2015). Prosopis cineraria are an imperative member of the arid, semiarid 
environments of the sub-tropical and tropical area around the world (Sushant et al., 2010). Maximum species of the Prosopis originate in the Americas, and the only four species of Prosopisis arising outside the America, in region like Southwest Asia and Africa (Atalano et al., 2008).

In Pakistan this species is found wildly and well adopted to the semiarid and arid condition of the Pakistan may be due to their well-developed and extensive tap root system, which reaches nearly to the length of $20 \mathrm{~m}$ habitually reaching out to the ground resources of the water (Gehlot et al., 2008). It becomes an important factor of the desert Ecosystem in the Pakistan as the biomass producer and as leguminous tree which enriches the desert soil, fixes atmospheric nitrogen and offers a green coverage. It donates to ecological constancy of the region and providing the wide support to human beings, nutrient deficient soils and the livestock (Chaudhry and Castle 2011). Furthermore, this plant species also provide remaining fuel wood for cooking and the heating in utmost households and restoration of despoiled lands in the arid and semiarid areas (Oduor and Githiomi 2013). All the closely related species of Prosopis keeps the similar morphology and their identification can be difficult, especially in the absence of fruit and flowers. In adding, the environment can have wide ranging effects on plant form, growth and leaf characteristics (Pasiecznik et al., 2001), and closely related species of Prosopis are known to crossbreed readily (Hunziker et al., 1986; Chaudhry, 2011).

Prosopis cineraria are one of the highly valued plant in the native system of medicine. It is also known to possess antibacterial, anthelmintic antifungal, anticancer antiviral and many other pharmacological qualities (Malik and Kalidhar, 2007). Prosopis cineraria an evergreen or nearly so, it forms an open crown and has thick, uneven grey bark with profound gaps (Rajesh et al., 2012). Its slim, glabrous and armed branches with prickles of 3-4 cm length, that is slightly compacted, straight and scattered. Flower is in the form of axillary spines with 7-11 cm length, either lonely or in terminal panicles. Flowers have yellow corolla, attracting a bulk of insects including great number of Apis florae and various other wild bees in December and April months (Gorain et al., 2012). It possesses bipinnately compound leaves, alternate in organization. The leaflets are 15-18 pairs, and designed rectangle with an entire margin, apiculate apex, obtuse base, glabrous surface, reticulate venation, petiolate, and the petiole is $0.5-4 \mathrm{~cm}$ long. The typical leaf size is $2.5 \mathrm{~cm}$ (length) and $1 \mathrm{~cm}$ (breadth). Morphologically, fresh leaves are green in colour, and are odorless with a bitter palatability (Dharani et al., 2011). The general phenological phase of Jhand, mainly flowering and fruiting will be in May-June of summer season. New leaf formation due to high protein content during end of summer (June-August) guarantees the availability of fodder to the livestock in severe summer period (Raj and Hooda, 1994; Chaudhry and Castle 2011). Their wood is valuable for making cart, house construction and agricultural tools (Gupta et al., 1998; Preek et al., 2015).

Existing shrinkage of forest area is due to some obvious factors. Clearing of forest for cultivation of farm crops and for fuel wood are among major factors. Our forest department, despite of their tiresome efforts are ineffective to raise the forest area even by $1 \%$ (FAO 2004). At this stage Pakistan is capable in forest resource even to meet growing local demand of wood. Pakistan is an agrarian country; the existing forests cover is only $4.8 \%$ of its area. This is very low as compared to desired ratio of $25 \%$ which is declared for sustained economic development and to encounter the wood demand of a country. The use of cutting is the best vital method for reproducing new 
plants. During the favourable situation cutting any isolated plant part that for rebirth will produce new plant similar to the parent plant (Singh et al., 2015). In this situation agro-forestry is best solution where the forest land cannot increase. In this way we can not only produce extra amount of wood to meet our domestic demands but can also complete the goals of exports for our valued wood product. It has been estimated that of our $10 \%$ farmland area can be brought under agro forestry without destroying of our farm crops.

In our land just about concerning 330 million timber standing throughout the entire farmland with the standing up with the amount of 70 million $\mathrm{m}^{3}$ (Qurashi, 1998; Kaushik and Kumar, 2003; FAO 2004). The vegetative reproduction has been one response. The capability to harness bigger genetic characters through the asexual reproduction is being observed in various forest tree development plans. This method of reproduction is fast becoming a very vital nursery controlling tool because of reduced time requirement for cutting of larger trees to root and grow (Hudson, 1997; Singh et al., 2007). The present work is best and easiest method to determine the method of producing plant of Prosopis cineraria from branch cutting. The root initiating hormones IBA were used for asexual propagation of Prosopis cineraria. The results of this research will play an important role in reducing the size of shoot being used in asexual propagation and it will also reducing the plant genotypic variability and will help to ensure increased germination percentage by determining the finest amount of root initiating hormones. The research was conducted to check the propagation potential in shoot cuttings of Prosopis cineraria collected from various locations in Cholistan desert. To check the individual effects at various concentrations of growth hormone like IBA in inducing the root formation in Prosopis cineraria cuttings. To relate the propagation potential of various sizes of cuttings as a growing stocks.

\section{Materials and methods}

The research work was carried out in the nursery area, Department of Forestry, Range and Wildlife Management, The Islamia University of Bahawalpur during the last week February in 2015. The site is located at the latitude $36^{\circ}-26^{\prime \prime} \mathrm{N}$ and longitude of $73^{\circ}-06$ ”'E. Altitude of site is $184.4 \mathrm{~m}$. Different sized cuttings of Prosopis cineraria were collected from a healthy tree of Prosopis cineraria from the various locations of Cholistan desert.

\section{Collection of plant samples}

Selection of tree was done on following phenotypic qualities.

(1) The age of tree should be between 20-25 years. (2) The plant which is selected should be disease free, with leaves and branches. (3) The selected plant should have more and straight bole. Approximately one year old branches of thumb thickness were selected.

\section{Size of cutting}

Cutting of three sizes i.e. $5.08 \mathrm{~cm}, 10.16 \mathrm{~cm}$ and $15.24 \mathrm{~cm}$ were prepared. While preparing, the cuttings were taken to avoid that the bark may not get damaged. Flush cutting was done to avoid the peeling away of the bark. A slanting cut was given on the upper end of cutting to avoid fungal attack. The cuttings were dipped in bleach solution carefully prepared at a ratio of 1: 4 in water. Cuttings were planting in polythene bags 
$(6 \mathrm{~cm} \times 18 \mathrm{~cm})$. These polythene bag were filled with silt, sand and clay in equal ratio, which acted as the rooted medium.

\section{Application of IBA}

Treating with root initiating hormone, the root initiating hormones, Indole butyric acid (IBA) were used in $4000 \mathrm{ppm}$. Basal 1/3 portion of cutting were dipped in the root initiating hormone solution for $16 \mathrm{~h}$ (Ram et al., 2013).

\section{Data collection}

Three parameters were studied along with their interaction. Following six treatments were applied to different cuttings. Only $15.24 \mathrm{~cm}$ cuttings were applied to the root initiating hormones, Indole butyric acid (IBA) in open air to check its effect on different growth parameters. Cuttings of different sizes $5.08 \mathrm{~cm}$ and $10.16 \mathrm{~cm}$ in pen air and under Polythene sheet were used. Cuttings were observed daily but the measurement were taken after every 7 days interval. The last reading was taken after sixty days. Data on Sprouting percentage, Number of leaves, Plant height and Root length were recorded during experiment.

\section{Statistical analysis}

Experiment was carried out according to CRD (Complete randomized design) (Steel et al., 1997).

\section{Results and discussion}

The present work was an effort to determine the best and easiest method of producing plants of Prosopis cineraria from branch cuttings. The root initiating hormone lndole butyric acid was applied on the branch cuttings of Prosopis cineraria. This research was an effort to reduce the size of shoot being used in vegetative propagation. This method reduces the plant genotypic variability.

\section{Sprouting percentage}

Sprouting percentage always plays an important role for a good future crop. If there is more sprouting it means the cultural practices you are doing and planting material used is satisfactory. Environmental conditions are also important for good sprouting. High sprouting percentage is the primary requirement for a good nursery business. Sprouting percentage is very important to predict the behaviour of the tree if any species is to be propagated by asexual method of shoot cutting. Good sprouting percentage is a perquisite for a healthy future crop stand. Analysis of variance for the sprouting per outing are given Table 1 and the comparison of means for the factors like cutting size and Growth hormones are given in Table 1 and overall sprouting \% age given in Table 1. From the results of the sprouting percentage it is clear that $15.24 \mathrm{~cm}$ cutting under growth regulator IBA gave the best result with sprouting. Overall $15.24 \mathrm{~cm}$ cutting at open air was found best $(2.38 \mathrm{C})$ in all the treatments as shown in Table 1 but it sprouted maximum in growth regulator IBA $(3.71 \mathrm{~A})$ as shown in Table $1.10 .16 \mathrm{~cm}$ cuttings were also good (3.12 B) in polythene sheet as shown in Table 1, but showed less sprouting than $15.24 \mathrm{~cm} .5 .08 \mathrm{~cm}$ cutting showed good sprouting in polythene and 
it was even lower in open air as shown in (fig. 1). Our findings are in the line of Ngo Mpeck et al. (2003), Wang et al. (1997) and Edson et al. (1991). Cuttings were observed very carefully and after 30 days sprouting percentage was calculated by (Mebrahtu and Hanover 1990).

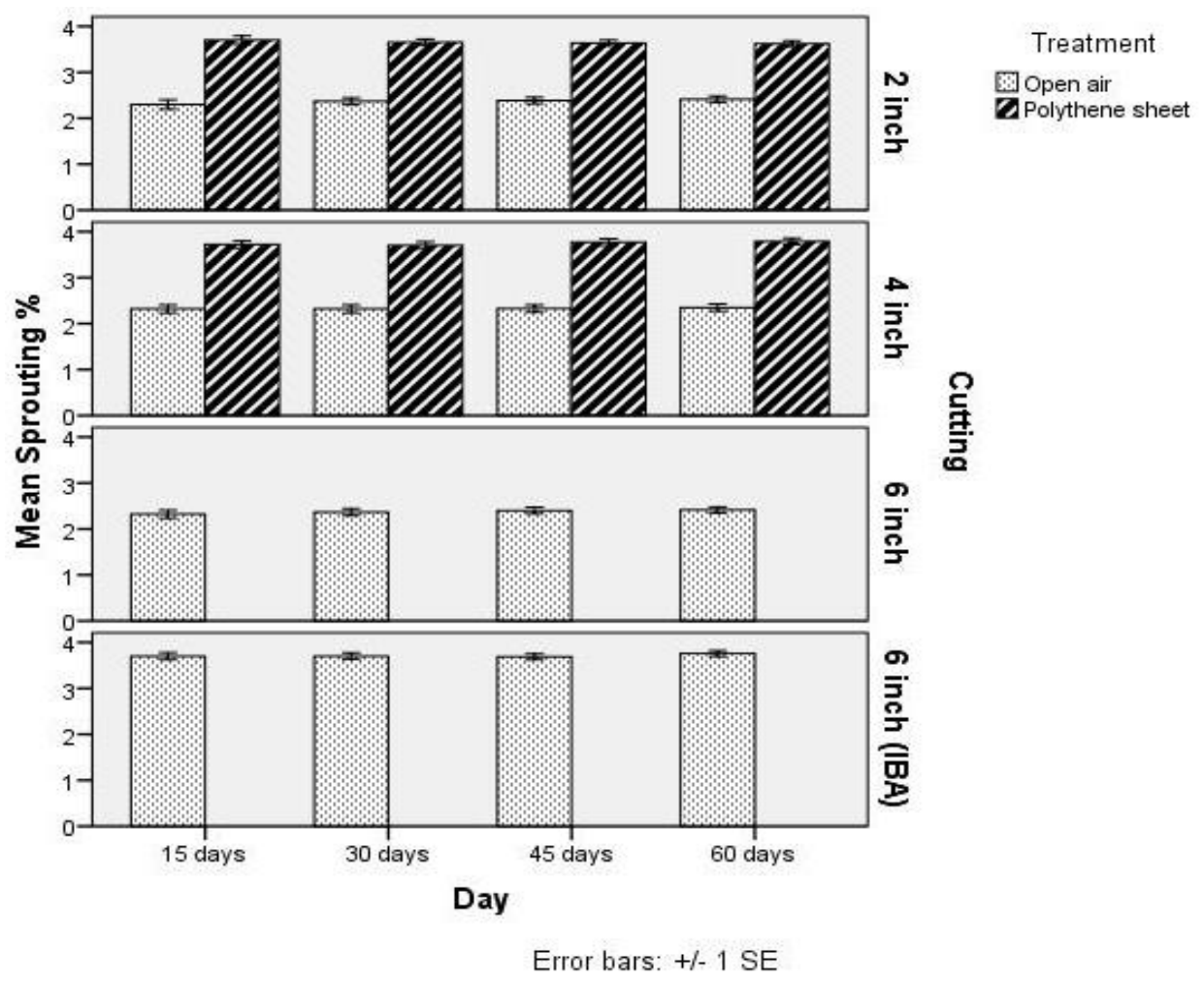

Figure 1. Sprouting percentage as affected by different cutting sizes

Table 1. Comparison between open air and polythene sheets regarding number of leaves, sprouting percentage, height $(\mathrm{cm})$ and root length $(\mathrm{cm})$ for overall data

\begin{tabular}{|c|c|c|c|c|c|c|c|}
\hline Parameter & Treatment & $\mathbf{N}$ & Mean & SD & SE & t-value & Prob \\
\hline \multirow{2}{*}{ No. of leaves } & Open air & 1005 & 3.04 & 0.958 & 0.030 & \multirow{2}{*}{$-19.37 * *$} & \multirow{2}{*}{0.000} \\
\hline & Polythene sheet & 571 & 3.93 & 0.684 & 0.029 & & \\
\hline \multirow{2}{*}{ Sprouting $\%$} & Open air & 1005 & 2.77 & 0.857 & 0.027 & \multirow{2}{*}{$-22.81 * *$} & \multirow{2}{*}{0.000} \\
\hline & Polythene sheet & 571 & 3.70 & 0.611 & 0.026 & & \\
\hline \multirow{2}{*}{ Height (cm) } & Open air & 1005 & 1.51 & 0.516 & 0.016 & \multirow{2}{*}{$-30.72 * *$} & \multirow{2}{*}{0.000} \\
\hline & Polythene sheet & 571 & 2.22 & 0.253 & 0.011 & & \\
\hline \multirow{2}{*}{ Root length $(\mathrm{cm})$} & Open air & 1005 & 1.50 & 0.497 & 0.016 & \multirow{2}{*}{$-30.68 * *$} & \multirow{2}{*}{0.000} \\
\hline & Polythene sheet & 571 & 2.16 & 0.166 & 0.007 & & \\
\hline
\end{tabular}

** = highly significant $(\mathrm{P}<0.01) ; \mathrm{N}=$ number of observations; $\mathrm{SD}=$ standard deviation; $\mathrm{SE}=$ standard error

\section{Number of leaves}

The number of leaves is important for the good growth of plants, if a plant has more leaves it means the plant will utilize the sunlight in a more efficient way and the plant 
overall will be healthy. Number of leaves also determines the growth of plants at nursery stage. The plant having more leaves are more vigorous in their growth and are stable than the plants having less number of leaves. Production of more number of leaves is also an important factor in determining the fodder value of the plant (Rafay et al., 2013). After 15 days under the individual factor highest number of leaves (4.21) was produced by the $15.24 \mathrm{~cm}$ cuttings with IBA as shown in Figure 2 and least was produced by the $5.08 \mathrm{~cm}$ cuttings in open air. Number of leave was produce (3.44) more in $10.16 \mathrm{~cm}$ cutting in polythene sheet as compared to open air as shown in Table 1. Different scientists observed that $15.24 \mathrm{~cm}$ cuttings growth is better and produce more number of leaves in plastic tunnels (Pomper et al., 2002). After 30, 45 and 60 days highest numbers of leaves were produces by the $15.24 \mathrm{~cm}$ cutting as shown in Figure 2 with growth hormone IBA in open air and the least number of leaves were produced by the $5.08 \mathrm{~cm}$ cutting in open air. In $10.16 \mathrm{~cm}$ cutting number of leaves are more as compared to $5.08 \mathrm{~cm}$ cutting in polythene sheet. Other scientists observed that under plastic sheets $15.24 \mathrm{~cm}$ cutting showed better growth and produce more number of leaves (Rafay et al., 2013).

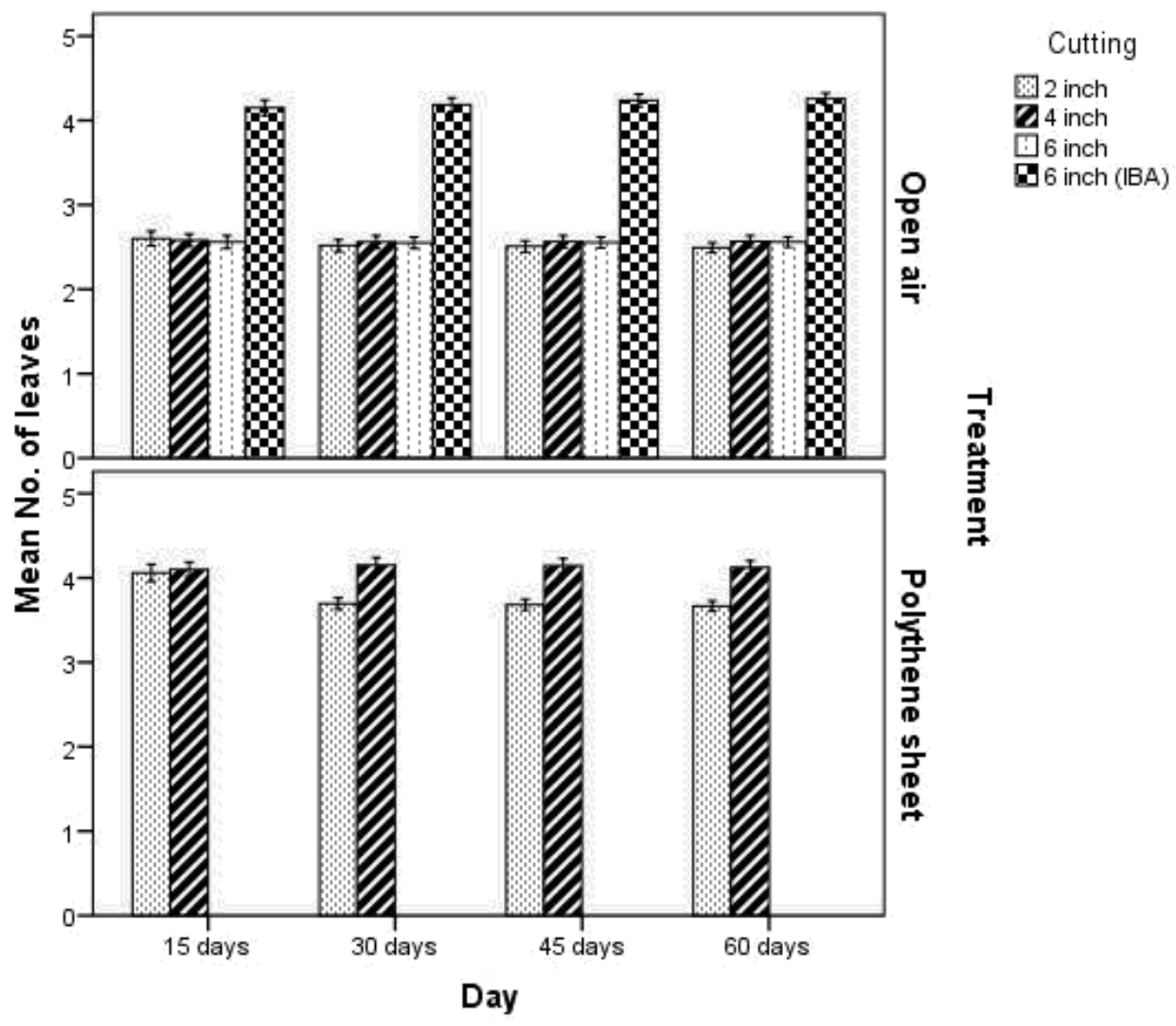

Error bars: $+\%$ - 1 SE

Figure 2. Mean comparison of leaves in different cutting size

\section{Plant height (cm)}

Plant height is measured in order to determine the total length of the plant (Root and Shoot). Plant height in open air after fifteen days showed its peak value $(2.20 \mathrm{~A})$ in $15.24 \mathrm{~cm}$ cutting with provided IBA and least height $(1.23 \mathrm{C})$ was noted in $15.24 \mathrm{~cm}$ 
cutting without growth regulator. Second peak value $(1.19 \mathrm{~B})$ in $5.08 \mathrm{~cm}$ cutting followed by $(1.19 \mathrm{~B})$ in $10.16 \mathrm{~cm}$ cutting. Plant height in polythene sheet after fifteen days showed its peak value $(2.20 \mathrm{~A})$ in $10.16 \mathrm{~cm}$ cutting and least height $(1.20 \mathrm{~A})$ was noted in $5.08 \mathrm{~cm}$ cutting. $10.16 \mathrm{~cm}$ cutting was noted to be highly significant as given in Figure 3. Plant height in open air after thirty days showed its peak value $(2.20 \mathrm{~A})$ in $15.24 \mathrm{~cm}$ cutting with provided IBA and least height $(1.19 \mathrm{~B})$ was noted in $10.16 \mathrm{~cm}$ cutting. Second peak value $(1.22 \mathrm{~B})$ in $15.24 \mathrm{~cm}$ cutting without growth regulator followed by $(1.20 \mathrm{~B})$ in $5.08 \mathrm{~cm}$ cutting. Plant height in polythene sheet after thirty days showed its peak value $(2.22 \mathrm{~A})$ in $5.08 \mathrm{~cm}$ cutting and least height $(2.20 \mathrm{~A})$ was noted in $10.16 \mathrm{~cm}$ cutting. $5.08 \mathrm{~cm}$ cutting was noted to be highly significant as given in Table 1. Plant height in open air after forty five days showed its peak value $(1.52 \mathrm{~A})$ in $15.24 \mathrm{~cm}$ cutting with provided IBA and least height $(1.19 \mathrm{~B})$ was noted in $10.16 \mathrm{~cm}$ cutting. Second peak value $(1.23 \mathrm{~B})$ in $15.24 \mathrm{~cm}$ cutting without growth regulator followed by $(1.22 \mathrm{~B})$ in $5.08 \mathrm{~cm}$ cutting. Plant height in polythene sheet after forty five days showed its peak value $(2.25 \mathrm{~A})$ in $5.08 \mathrm{~cm}$ cutting and least height $(2.19 \mathrm{~A})$ was noted in $10.16 \mathrm{~cm}$ cutting. In these factors the factor A of $5.08 \mathrm{~cm}$ cutting was noted to be highly significant as given in Table 1. Plant height in open air after sixty days showed its peak value $(2.21 \mathrm{~A})$ in $15.24 \mathrm{~cm}$ cutting with provided IBA and least height $(1.21 \mathrm{~B})$ was noted in $10.16 \mathrm{~cm}$ cutting. Second peak value $(1.25 \mathrm{~B})$ in $15.24 \mathrm{~cm}$ cutting without growth regulator as well as $(1.25 \mathrm{~B})$ in $5.08 \mathrm{~cm}$ cutting. In these factors the factor A was found to be highly significant as given in Table 1. Plant height in polythene sheet after sixty days showed its peak value $(2.26 \mathrm{~A})$ in $5.08 \mathrm{~cm}$ cutting and least height $(2.20 \mathrm{~A})$ was noted in $10.16 \mathrm{~cm}$ cutting. $5.08 \mathrm{~cm}$ cuttings were noted to be highly significant as given in Table 1 (Figs. 4 and 5).

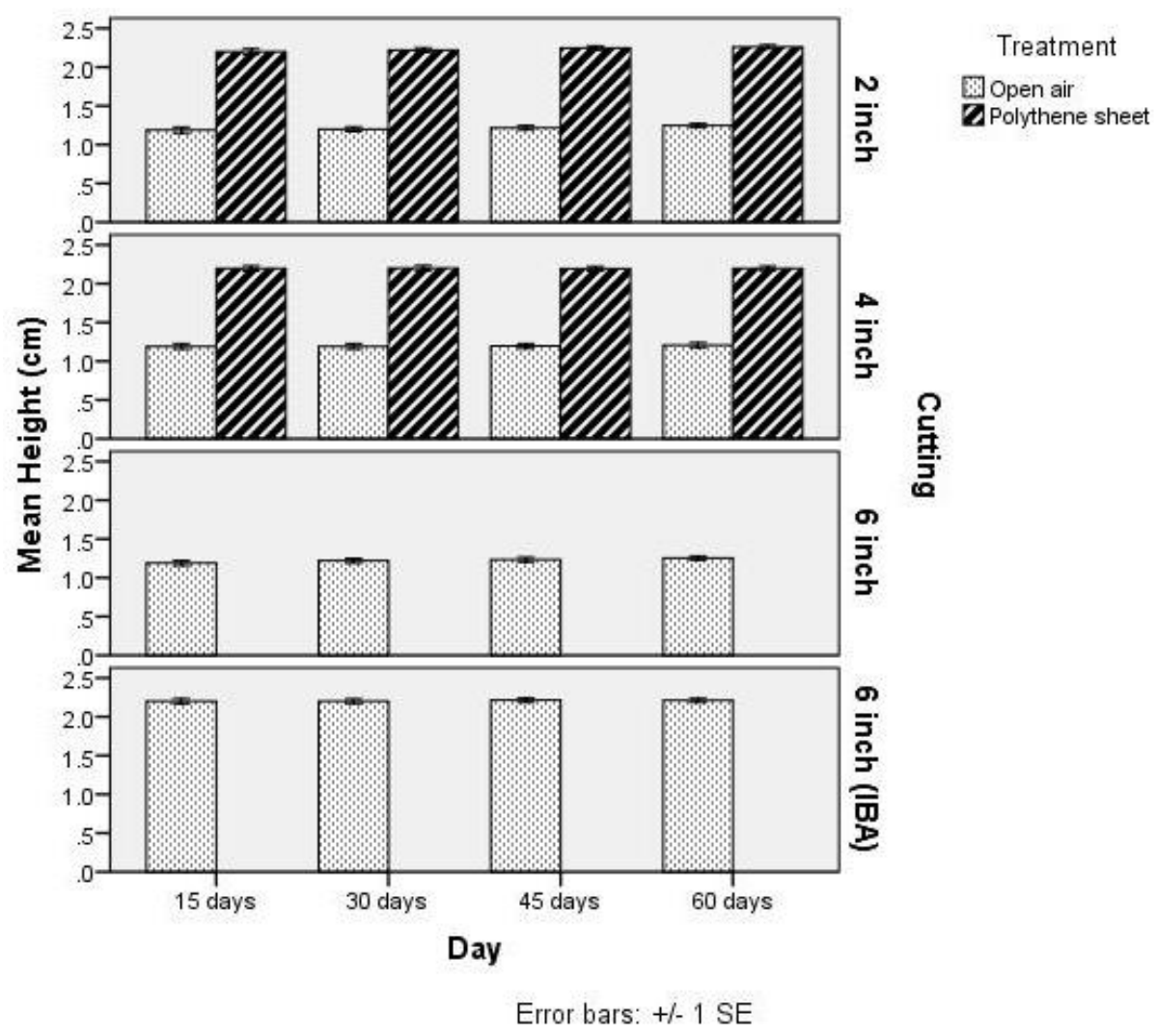

Figure 3. Height affected by different cutting sizes 


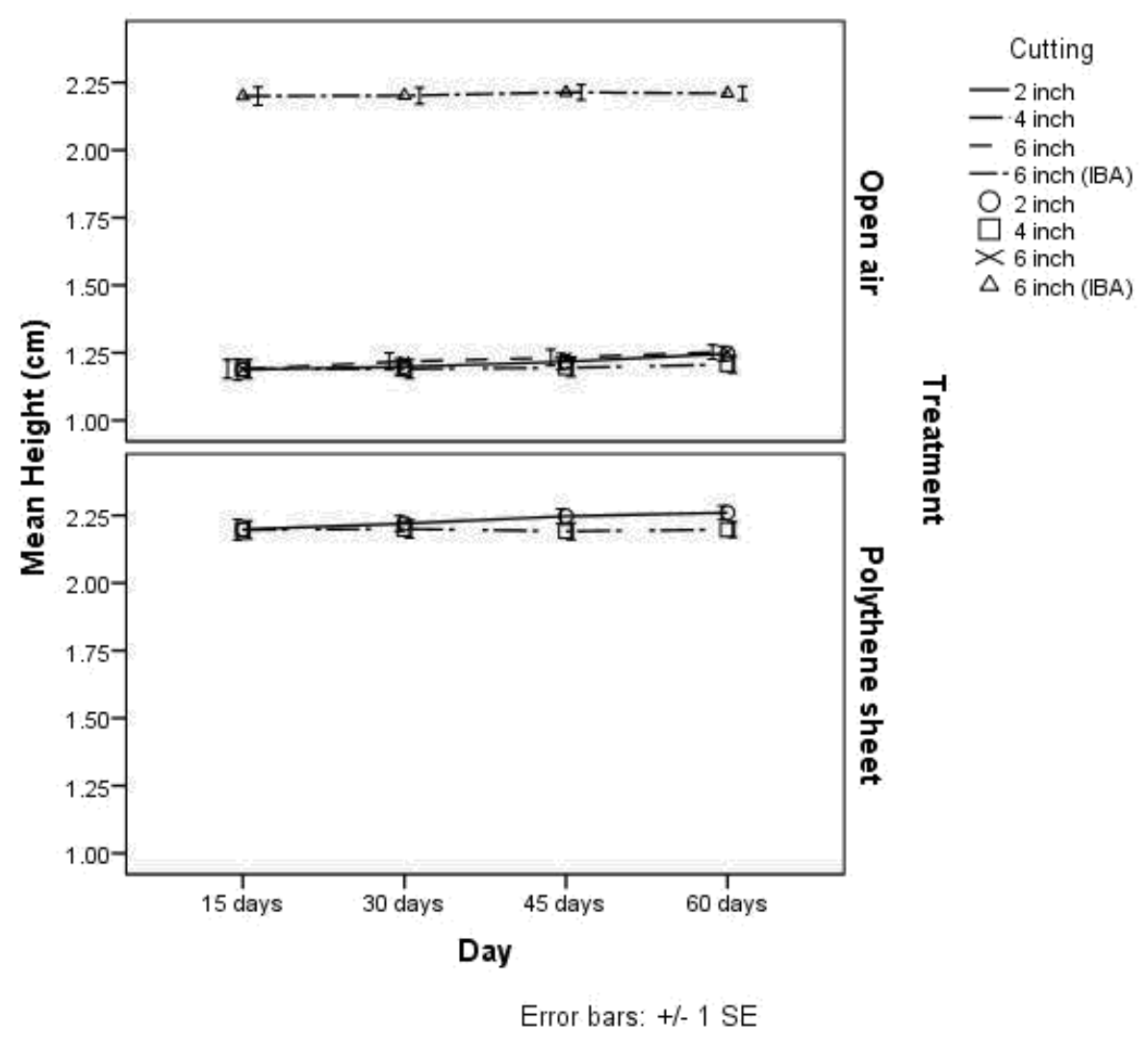

Figure 4. Height in open air and polythene sheet

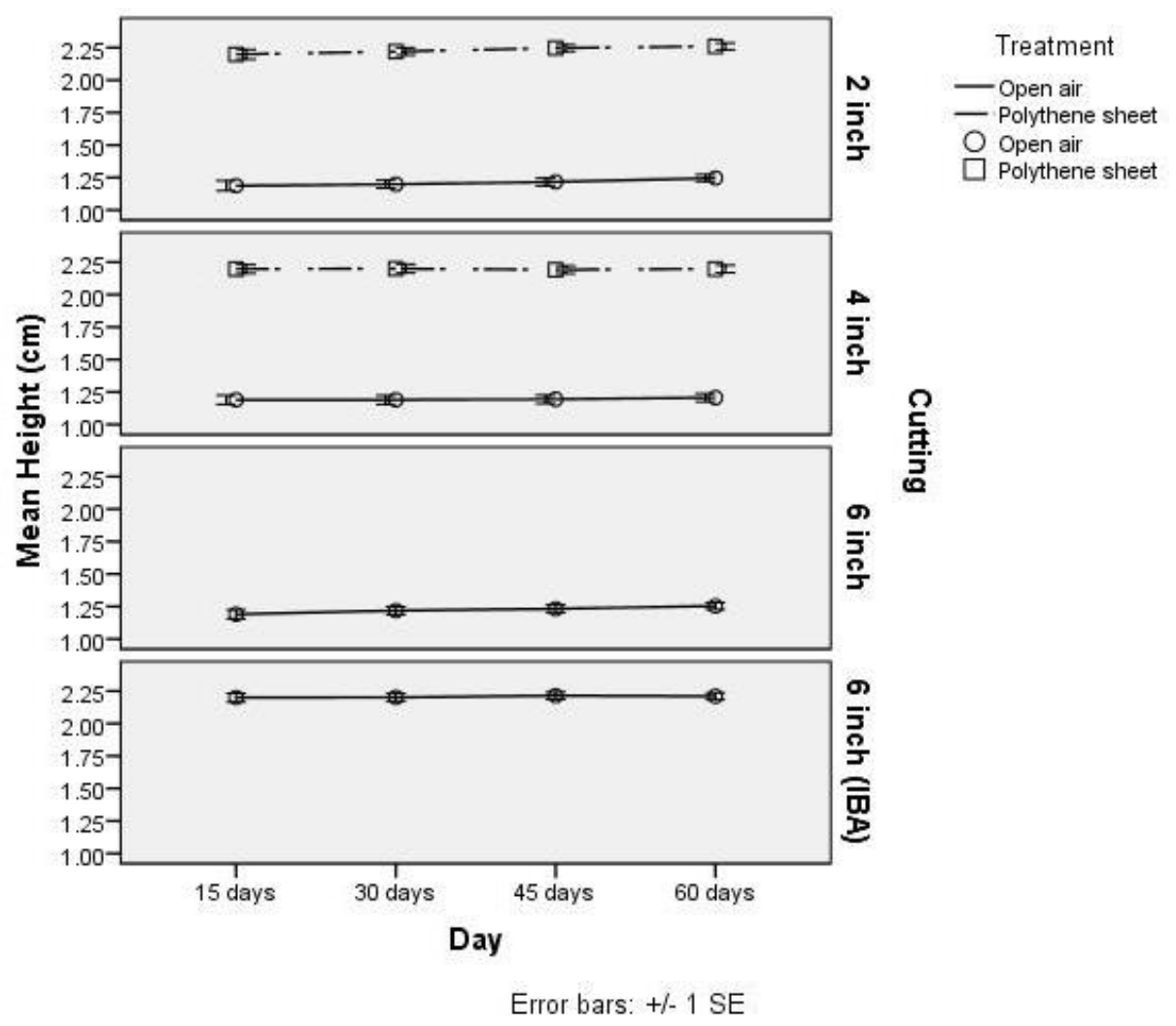

Figure 5. Height affected by different cutting size 


\section{Root length (cm)}

Root is the basic organ, which plays a vital role in the plant development. Roots not only provide anchorage to the plant but also absorb important nutrients which are essential for the growth of the plant. A root goes deeper into the soil and explores the soil mass for more and more nutrients. Root length determines the growth of the plant. The plants having healthy and more vigorous roots are healthier than those with weak root system. Good plant root system developed at the early stages of plat growth is the prerequisite for the good survival percentage of the crop. Analysis of variance for the root length in open air taken after 15 days and mean comparison of 5\% level of significant is given in the Table 1. Analysis of variance for the root length in polythene sheets taken after 15 days and mean comparison of 5\% level of significant is given in the Table 1. Root Length in open air after fifteen days showed its peak value $(2.14 \mathrm{~A})$ in $15.24 \mathrm{~cm}$ cutting with provided IBA and least height $(1.19 \mathrm{~B})$ was noted in $5.08 \mathrm{~cm}$ cutting as shown in Table 1. After that $(1.20 \mathrm{~B})$ value was recorded in $10.16 \mathrm{~cm}$ cutting as well as in $15.24 \mathrm{~cm}$ cutting without growth regulator. Root Length in polythene sheet after fifteen days showed its peak value $(2.14 \mathrm{~A})$ in $10.16 \mathrm{~cm}$ cutting and least height (2.14 A) was noted in $5.08 \mathrm{~cm}$ cutting (Fig. 6).

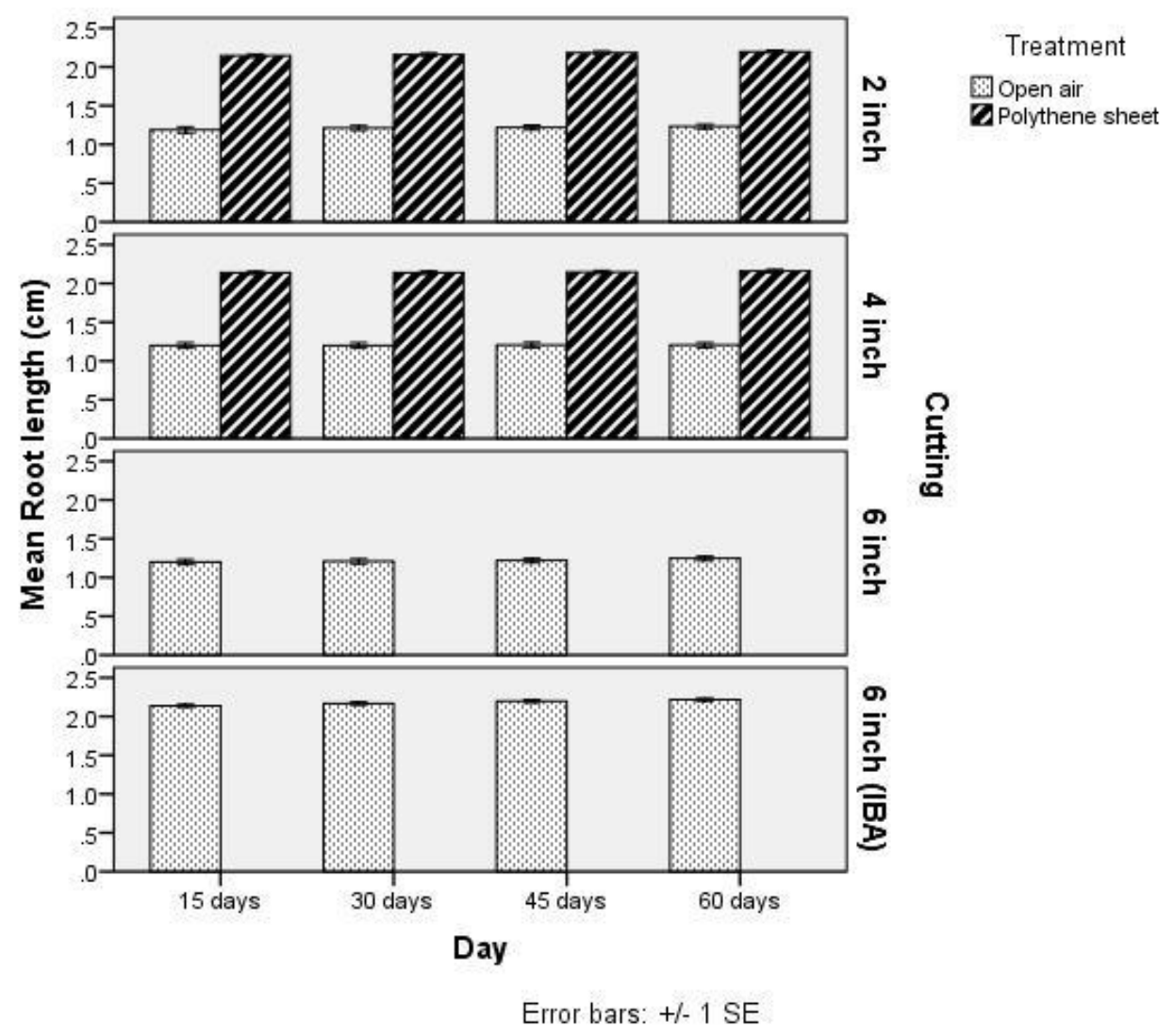

Figure 6. Root length in open air and polythene sheet

Analysis of variance for the root length in open air taken after thirty days and mean comparison of 5\% level of significant is given in Table 1. Analysis of variance for the root length in polythene sheets taken after thirty days and mean comparison of 5\% level of significant is given in Table 1. Root Length in open air after thirty days showed its 
peak value $(2.17 \mathrm{~A})$ in $15.24 \mathrm{~cm}$ cutting with provided IBA and least height $(1.20 \mathrm{~B})$ was noted in $10.16 \mathrm{~cm}$ cutting. After that $(1.21 \mathrm{~B})$ value was recorded in $5.08 \mathrm{~cm}$ cutting as well as in $15.24 \mathrm{~cm}$ cutting without growth regulator. Root Length in polythene sheet after thirty days showed its peak value $(2.16 \mathrm{~A})$ in $5.08 \mathrm{~cm}$ cutting and least height $(2.14 \mathrm{~A})$ was noted in $10.16 \mathrm{~cm}$ cutting. Analysis of variance for the root length in polythene sheets taken after forty five day and mean comparison of 5\% level of significant is given in Table 1. Root Length in open air after forty five days showed its peak value $(2.20 \mathrm{~A})$ in $15.24 \mathrm{~cm}$ cutting with provided IBA and least height $(1.21 \mathrm{~B})$ was noted in $10.16 \mathrm{~cm}$ cutting. After that $(1.22 \mathrm{~B})$ value was recorded in $5.08 \mathrm{~cm}$ cutting as well as in $15.24 \mathrm{~cm}$ cutting without growth regulator. Root Length in polythene sheet after forty five days showed its peak value $(2.18 \mathrm{~A})$ in $5.08 \mathrm{~cm}$ cutting and least height $(2.14 \mathrm{~A})$ was noted in $10.16 \mathrm{~cm}$ cuttings. Root Length in open air after sixty days showed its peak value $(2.22 \mathrm{~A})$ in $15.24 \mathrm{~cm}$ cutting with provided IBA and least height $(1.21 \mathrm{~B})$ was noted in $10.16 \mathrm{~cm}$ cutting. After that $(1.25 \mathrm{~B})$ value was recorded in $15.24 \mathrm{~cm}$ cutting without growth regulator followed by $(1.23)$ in $5.08 \mathrm{~cm}$ cutting. Root Length in polythene sheet after sixty days showed its peak value $(2.20 \mathrm{~A})$ in $5.08 \mathrm{~cm}$ cutting and least height $(2.16 \mathrm{~A}$ ) was noted in $10.16 \mathrm{~cm}$ cutting. Jhand is a desert tree species and it is a difficult species to root unlike Teerminalia chebula which sprouted after 30 days (Jose and thomas 1998). Best rooting was observed in IAA, which is in contradiction with the other scientists who found IBA, the most effective auxin (Palanisamy et al., 1998; Reddy et al., 1998; Hee et al., 1997; McGuigan et al., 1996; Wang et al., 1997).

\section{Conclusions}

Indole Butyric Acid (IBA) was used to determine the different parameter including the sprouting percentage, number of leaves, plant height and root length. In open air experiment, $15.24 \mathrm{~cm}$ cuttings showed excellent results. Maximum number of leaves during air experiment by using $15.24 \mathrm{~cm}$ cuttings were $4.21 \mathrm{~A}$. similarly sprouting was maximum at $3.71 \mathrm{~A}$ in open air. Best height was obtained from $15.24 \mathrm{~cm}$ cuttings with 2.21 A. Root length at 2.18 A for $15.24 \mathrm{~cm}$ cuttings were maximum. During open air experiment it was observed that numbers of leaves were reduced with the reduction in cutting size. While under polythene sheet at 3.44 A maximum number of leaves was produced by using $10.16 \mathrm{~cm}$ cuttings. Maximum heights were obtained from $15.24 \mathrm{~cm}$ cuttings with 2.21 A. minimum height was shown from $15.24 \mathrm{~cm}$ cuttings without regulator. So these treatments showed best result for maximum growth, sprouting, heights and number of leaves of Prosopis cineraria. We can get desired plant by applying these conditions on our nursery to ensure better results in future.

\section{REFERENCES}

[1] Atalano, S., Vilardi, J., Tosto, D., Saidman, B. (2008): Molecular phylogeny and diversification history of Prosopis (Fabaceae: Mimosoideae). - Biological Journal of the Linnean Society 93(3): 621-640.

[2] Chaudhry, Q., Castle, L. (2011). Food applications of nanotechnologies: an overview of opportunities and challenges for developing countries. Trends in Food Science \& Technology, 22(11), 595-603. 
[3] Chaudhry, P. (2011). Prosopis cineraria (L) Druce: A life line tree species of the Thar Desert in danger.

[4] Dharani, B., Sumathi, S., Sivaprabha, J., Padma, P. R. (2011): In vitro antioxidant potential of Prosopis cineraria leaves. - J. Nat. Prod. Plant Resource 1(3): 26-32.

[5] Edson Jhon, L., Wenny David, L., Lauren, F. (1991): Propagation of western larch by stem cutting. - Western Journal of Applied Forestry 6(2): 115-125.

[6] FAO (2004): Introduction. National forest products Statistics, Pakistan. http//www.fao.org./DOCREP/005AC778E15.html.

[7] Gehlot, P., Bohra, N. K., Purohit, D. K. (2008): Endophytic mycoflora of inner bark of Prosopis cineraria - a key stone tree species of Indian desert. - American-Eurasian Journal of Botany 1(1): 1-4.

[8] Gorain, M., Charan, S. K., Ahmed, S. I. (2012): Role of insect bees in the pollination of Prosopis cineraria (L.) Druce (Leguminosae, Subfamily Mimosideae) in Rajasthan. Advances in Applied Science Research 3(6): 3448-3451.

[9] Gupta, G. N., Singh, G., Kachwaha, G. R. (1998): Performance of Prosopis cineraria and associated crops under varying spacing regimes in the arid zone of India. - Agr. Sys. 40: 149-157.

[10] Hee, H. B., Young, J. H., Young, K. J. (1997): In vitro propagation of Ficus benjimana by shoot tip culture. - Journal of Korean Society for Horticultural Sciences 38(3): 315319.

[11] Hudson, K. (1997): Overview of Cutting Propagation. - FY 614, 3/7/97. University of Auburn, Auburn, AL.

[12] Hunziker, J., Saidman, B. O., Naranjo, C. A., Palacios, R. A., Poggio, L., Burghardt, A. D. (1986): Hybridization and genetic variation of Argentine species of Prosopis. - Forest Ecology and Management 16: 301-315.

[13] Jose, P., Thomas, A. J. (1998): An account of the vegetative propagation in Terminalia chebula Retz. - Indian forester 124(5): 357-359.

[14] Kaushik, N., Kumar, V. (2003): Khejri (Prosopis cineraria)-based agroforestry system for arid Haryana, India. - Journal of Arid Environments 55(3): 433-440.

[15] Liu, Y., Singh, D. and Nair, M. G. (2012): Pods of Khejri (Prosopis cineraria) consumed as a vegetable showed functional food properties. - Journal of Functional Foods 4(1): 116-121.

[16] Mahoney, D. (1990): Trees of Somalia - A Field Guide for Development Workers. Oxfam/HDRA, Oxford, pp. 133-136.

[17] Malik, A., Kalidhar, S. B. (2007): Phytochemical investigation of Prosopis cineraria L. (Druce) leaves. - Indian Journal of Pharmaceutical Science 69: 576-578.

[18] McGuigan, P. J., Blazich, F. A., \& Ranney, T. G. (1996). Propagation of Quercus myrsinifolia and Quercus canbyi by stem cuttings. Journal of Environmental Horticulture, 14(4), 217-220.

[19] Mebrahtu, T., Hanover, J. W. (1990): The effect of root cutting size on the time of sprouting of Black Locust. - Nitrogen Fixing Trees Research Report 8: 156-158.

[20] Mpeck, M.-L., Tchoundjeu, Z., Asaah, E (2003): Vegetative propagation of Pausinystalia johemble k. Schum. By leafy stem cuttings. - Propagation of ornamental plants 3(2): 11-18.

[21] Oduor, N. M., Githiomi, J. K. (2013) Fuel-wood energy properties of Prosopis juliflora and Prosopis pallida grown in Baringo District, Kenya. - African Journal of Agricultural Research 8(21): 2476-2481.

[22] Palanisamy, K., Ansari, S. A., Kuma, P., Gupta, B. (1998): Adventitious root in shoot cuttings of Azadirachta indica and Pogamia pinnata. - New Forest 16(1) 81-88.

[23] Pasiecznik, N. M., Felker, P., Harris, P. J., Harsh, L., Cruz, G., Tewari, J. C., ... \& Maldonado, L. J. (2001). The' Prosopis juliflora'-'Prosopis pallida'complex: a monograph (Vol. 172). Coventry: HDRA. 
[24] Pomper, K. W., Layne, D. R., Jones, S. C. (2002): Incidence Irradiance and cupric hydroxide container treatment effects on early growth and development of container Grown Pawpaw seedling. - J. Amer. Soc. Hort. Sca. 127(1): 13-19.

[25] Preek, A. K., Garg, S., Kuma, M. (2015): Prosopis cineraria: a gift of nature for pharmacy. - Int. J. Pharma Sci. Res. 6(6): 958-964.

[26] Puri, S., Kumar A. (1995): Establishment of Prosopis cineraria (L.) Druce in the hot deserts of India. - New forests 9: 21-33.

[27] Qurashi Masood, A. A. (1998): Basic of Forestry and Allied Sciences. Vol. 1. Department of Forestry, University of Agriculture Faisalabad.

[28] Rafay, M., Khan, R. A., Yaqoob, S., Ahmad, M. (2013): Nutritional evaluation of major range grasses from Cholistan Desert. - Pakistan Journal of Nutrition 12: 23-29.

[29] Raj, B., Hooda, M. S. (1994): Studies on phenology and breeding system of Jand (Prosopis cineraria (L.) Druce). - Crop Res. 7(3): 473-478.

[30] Rajesh., K., Verma, K. S., Chaturvedi, O. P., Alam, N. M. (2012): Leaf litter decomposition and nutrient dynamics in four multipurpose tree species. - Range Management and agroforestry 33(1): 20-27.

[31] Ram, Newaj ., Dhyani, S., Badre, K., Ajit, A., Rajendra, P., Handa, A. K., Upendra, K., Shikha, N. (2013): Long term effect of root management practices on rooting pattern in Dalbergia sissoo and grain yield of mustard under agrisilviculture system. - Range Management and Agro Forestry 34(1): 47-50.

[32] Reddy, P. S. A., Rajasekhar, G., Gopal, R. (1998): Vegetative propagation of Acacia concinna DC by stem cutting. - Indian forester 124(3): 264-266.

[33] Singh, G., Mutha, S., Bala, N. (2007): Effect of tree density on productivity of a Prosopis cineraria agroforestry system in North Western India. - Journal of Arid Environments 70(1): 152-163.

[34] Singh, Y. P., Vijay, D., Malaviya, D. R. (2015): Effect of cutting management on seed yield and quality attributes of tetraploid berseem. - Range Management and Agro Forestry 36(1): 47-51.

[35] Steel, R. G. D., Torrie, J. H., Dickey, D. A. (1997): Principles and Procedures of Statistics: A Biometrical Approach. $3^{\text {rd }}$ Ed. - McGraw Hill, New York, pp. 400-428.

[36] Sushant, S., Rajdavinder, K., Soodan, A. S. (2010): Morphology of diaspores of some range grasses of Punjab. - Range Management and Agroforestry 31(1): 52-58.

[37] Wang, X., Wang, J., Wang, Y., Dong, X., Chang, G., Cui, Z., Wang, X. S., Wang, Y. C., Dong, X. G., Chang, G. S., Cui, Z. L. (1997): Effect of cutting length on rooting and growth of two year old plants of Larixka empferi in nursery. - Forest Research 10(6): 659-662. 